\title{
PRÁTICAS DE BIOSSEGURANÇA NO ENSINO TÉCNICO DE ENFERMAGEM
}

\author{
BIOSECURITY PRACTICES IN TECHNICAL NURSING EDUCATION
}

PRÁCTICAS DE BIOSEGURIDAD EN LA ENSEÑANZA TÉCNICA DE ENFERMERÍA

\author{
Gerusa Ribeiro $^{1}$ \\ Denise Elvira Pires de Pires ${ }^{2}$ \\ Magda Duarte dos Anjos Scherer ${ }^{3}$
}

Resumo A biossegurança é um componente central a ser considerado para que os profissionais executem suas atividades minimizando danos à sua saúde e à de usuários dos serviços de saúde. As instituições educacionais e os(as) enfermeiros(as) docentes têm papel fundamental nesse processo. Com o objetivo de compreender a prática da biossegurança realizada por enfermeiros(as) docentes durante a supervisão de estágio de alunos de cursos técnicos de enfermagem, realizou-se uma pesquisa exploratória descritiva, de abordagem qualitativa. Os dados foram coletados no ano de 2012, com 11 enfermeiros(as) docentes de duas instituições da rede federal de educação profissional, científica e tecnológica na região Sul do Brasil. Utilizou-se triangulação metodológica com dados coletados por meio de estudo documental, entrevista semiestruturada e observação, orientados pela análise temática de conteúdo de Bardin. Os resultados mostraram que as ações dos docentes em relação à biossegurança são influenciadas pela disponibilidade e acesso aos materiais e equipamentos, pela quantidade e qualidade dos equipamentos de proteção individual, pela infraestrutura das instituições assistenciais e laboratórios de ensino e pelo conhecimento do tema. Concluiu-se que as ações protetoras na prática docente são influenciadas pelo conhecimento, pelas condições de trabalho e pelas escolhas dos sujeitos.

Palavras-chave exposição a agentes biológicos; biossegurança; enfermagem; educação técnica em enfermagem; saúde do trabalhador.
Abstract Biosecurity is a central component to be taken into account in order for professionals to undertake their activities while minimizing damage to their health and to health service users. Educational institutions and teaching nurses play a fundamental role in this process. A qualitative descriptive exploratory research study was carried out to understand the teaching nurses' biosecurity practices during the supervision of the internship of students taking technical courses in nursing. Data were collected in 2012, with 11 teaching nurses from two institutions in the federal network of professional, scientific, and technological education in Southern Brazil. Methodological triangulation was done with data collected through a documental study, semi-structured interviews, and observation, guided by thematic content analysis of Bardin. The results showed that the teachers' actions in biosecurity are influenced by the availability of and access to materials and equipment, by the amount and quality of personal protective equipment, by the infrastructure of the healthcare institutions, by care institutions and teaching laboratories, and by their knowledge on the subject. It was concluded that the protective actions in the teaching practice are influenced by knowledge, by working conditions, and by the choice of subjects.

Keywords exposure to biological agents; biosecurity; nursing; technical education in nursing; worker's health. 


\section{Introdução}

Trabalhar no campo da saúde implica cuidar de pessoas que, em determinado momento de suas vidas, adoeceram ou necessitam de cuidados profissionais. Trata-se de trabalho complexo, realizado em diversos cenários assistenciais, tais como emergência, centro cirúrgico, obstetrícia, que requerem a utilização e o manuseio de instrumentais para execução de procedimentos, como seringas e agulhas, materiais de curativos, até os mais sofisticados como respiradores, sondas e cateteres, sempre exigindo competências apropriadas para o fazer.

O trabalho em enfermagem é parte do processo de trabalho em saúde (Pires, 2009), devendo ser prestado de forma segura, para si, para os outros e para o meio ambiente, elementos fundamentais para a qualidade do trabalho nesses serviços. Tanto as práticas terapêuticas quanto o contato com os usuários doentes expõem os profissionais a riscos de acidentes ou adoecimento, e a biossegurança é um componente central a ser considerado para que os profissionais possam executar suas atividades minimizando danos que comprometam a sua saúde e a de quem é cuidado. As instituições educacionais e os(as) enfermeiros(as) docentes têm papel fundamental nesse processo.

O tema biossegurança surge com a moderna biotecnologia nos Estados Unidos nos anos 1970, pela necessidade de elaborar normas sobre a segurança do trabalho em laboratórios de manipulação genética. Em 1975, no Centro de Convenções de Asilomar, na Califórnia, o termo foi cunhado, oportunizando discussões sobre a proteção de pesquisadores e demais profissionais envolvidos em projetos com material biológico, sendo considerado um marco na preocupação com os riscos a que estão expostos os trabalhadores, a sociedade e o meio ambiente (Oda e Santos, 2012; Costa e Costa, 2003).

A biossegurança possui duas faces: uma referente à manipulação de DNA e pesquisas com células-tronco embrionárias, que dizem respeito à biossegurança legal; e a outra, a biossegurança praticada, presente em hospitais, universidades e consultórios, entre outros locais (Costa e Costa, 2003). Apresenta estreita relação com os diversos campos e disciplinas da ciência e interface com várias áreas, como a legislação trabalhista e sanitária, a engenharia, a agricultura, a química e a exobiologia. A sua definição ampliada considera a preservação da saúde pública e do meio ambiente no sentido de segurança da vida (biosafety), o que permite avanços na produção tecnológica visando à proteção da saúde humana, animal e do meio ambiente (Hirata, 2012; Wong, 2009; Pereira et al., 2009).

No Brasil, a biossegurança praticada no campo da saúde é amparada por ações da Agência Nacional de Vigilância Sanitária (Anvisa), da Comissão de Biossegurança em Saúde (CBS) do Ministério da Saúde, criada pela 
portaria GM/MS n. 1.683, de agosto de 2003 (Brasil, 2003), e em especial pela norma regulamentadora n. 32 (NR-32), de 2005, do Ministério do Trabalho e Emprego, que trata da segurança e saúde no trabalho em serviços de saúde (Coren/SC, 2011; Brasil, 2005a, 2005b).

A aplicação das normas de biossegurança depende da existência de políticas e regulamentos que orientem o fazer seguro, do conhecimento acerca do tema, da disponibilidade de infraestrutura, de políticas institucionais e de equipamentos de proteção individual (EPIs) e coletiva (EPCs). No entanto, o exercício de cada atividade de trabalho é uma dramática complexa, na qual múltiplos elementos interatuam, incluindo os cenários concretos, as políticas prescritas, os valores e os conhecimentos dos sujeitos, influenciando as escolhas nos contextos com diferentes possibilidades de ação.

As normas e exigências produzidas nos diversos níveis institucionais e pelos trabalhadores no sentido de antecipar o agir não são suficientes para que a prática da biossegurança se efetive. Na situação de trabalho, é preciso articular os conhecimentos e a experiência vivida na relação com os recursos e constrangimentos do meio para tomar a boa decisão do que fazer no 'aqui e agora'. O trabalhador integra, durante a atividade, seus valores e sua própria história sempre singular, na relação com a variabilidade advinda do ambiente de trabalho, o que torna cada contexto também singular (Brito et al., 2011; Schwartz e Durrive, 2010). Nesse sentido, contrário ao que previa o taylorismo, as normas antecedentes são sempre em alguma medida renormalizadas pelo trabalhador na realização da atividade (Schwartz e Durrive, 2010).

O trabalho da enfermagem no Brasil é desenvolvido por enfermeiros(as), técnicos(as) e auxiliares de enfermagem, cabendo ao(à) enfermeiro(a) a responsabilidade do trabalho desenvolvido pela equipe nas dimensões cuidar, educar/pesquisar e gerenciar. O conhecimento técnico e político-profissional dos(as) enfermeiros(as) influencia a formação de novos profissionais.

No Brasil, o número de técnicos de enfermagem (TEs) tem crescido significativamente, passando de $6,6 \%$ do total da força de trabalho na área em 1983 para 40\% em 2012. Nos estados do extremo sul do Brasil, até junho de 2016 os(as) TEs representavam, em Santa Catarina, 62,1\% do total da força de trabalho, e 66,2\% no Rio Grande do Sul, o que demonstra a importância dos TEs na profissão (Conselho Regional de Enfermagem de Santa Catarina, 2016; Conselho Regional de Enfermagem do Rio Grande do Sul, 2016). Diante do exposto, o presente estudo, motivado pelo reconhecimento da importância da realização de práticas biosseguras, pela constatação de que o TE representa grande contingente da força de trabalho em enfermagem e de que a formação é elemento estratégico para um fazer seguro, buscou compreender a prática da biossegurança realizada por enfermeiros(as) docentes de cursos técnicos de enfermagem durante a prática supervisionada de estágio. 
Triangulação metodológica para coleta e análise de dados: estudo documental, entrevistas semiestruturadas e observação

A pesquisa que deu origem a este artigo foi exploratória e descritiva, 4 de abordagem qualitativa, no sentido formulado por Polit, Beck e Hungler (2011), desenvolvida durante dois meses de 2012 em um estado da região Sul do Brasil. Incluiu o universo dos docentes de enfermagem de duas instituições de ensino técnico profissionalizante que compõem a Rede Federal de Educação Profissional, Científica e Tecnológica do estado, e se encontravam em atividade prática supervisionada no período do estudo. Totalizou 11 docentes do curso técnico do campus 1 e do campus 2, correspondendo, respectivamente, a 30\% e 90\% do total de enfermeiros(as) docentes de cada curso. Os(As) enfermeiros(as) tinham idades entre 24 e 45 anos, todos especialistas na área da educação, sete mestres (dois em fase de conclusão) e dois doutorandos; estes ministravam diferentes conteúdos da formação do técnico em enfermagem. Somente um era do sexo masculino.

Para a definição dos locais do estudo utilizou-se o critério de conveniência, considerando a facilidade de acesso da pesquisadora à referida rede federal. Inicialmente, pretendia-se incluir escolas públicas e privadas e circunscrever a pesquisa a uma região do estado. Em face das dificuldades de autorização por parte das escolas privadas, o estudo foi restrito ao ensino tecnológico público federal, mas ampliada a abrangência para duas regiões do estado. O critério de intencionalidade foi utilizado para a escolha dos sujeitos, incluindo: todos(as) os(as) docentes enfermeiros(as) dos cursos técnicos profissionalizantes lotados(as) nos dois campi, e que estivessem realizando atividade prática supervisionada no período proposto para a coleta dos dados.

Os institutos federais são instituições educacionais públicas, fazem parte da Rede Federal de Educação Profissional, Científica e Tecnológica, e são vinculados ao Ministério da Educação por meio da Secretaria de Educação Profissional e Tecnológica (Setec). Atuam em todos os níveis e modalidades de ensino, sendo especializados na oferta de educação profissional e tecnológica. As suas ações têm como meta a justiça social, a equidade, a competitividade econômica e a geração de novas tecnologias, com capacidade e competência para retribuir de forma rápida e dinâmica as demandas pela formação profissional (Brasil, 2008a).

Utilizou-se a triangulação metodológica (Minayo, Assis e Souza, 2006; Minayo e Gomes, 2012) na coleta e análise dos dados, por meio de estudo documental, entrevistas semiestruturadas e observação. Para auxiliar na compreensão da realidade, foram estudadas as leis, resoluções e normas 
relativas à biossegurança e ao exercício profissional da enfermagem, os planos pedagógicos dos cursos (PPCs) dos dois campi e o Catálogo Nacional dos Cursos Técnicos (Brasil, 2008b).

As entrevistas seguiram um roteiro que buscou identificar aspectos do processo de educar que influenciam as práticas de biossegurança, incluindo o cenário dos campos de estágio, a disponibilidade de materiais e equipamentos de segurança, o conhecimento acerca do tema, a organização dos ambientes, assim como as escolhas dos sujeitos na aplicação das normas. As observações foram realizadas em seis hospitais, três unidades de pronto atendimento/pronto atendimento (UPAs/PAs), uma unidade básica de saúde (UBS) e um centro de atenção psicossocial (Caps), durante o período de desenvolvimento das atividades práticas, em diferentes dias e turnos da semana, de acordo com o cronograma dos campi, perfazendo média de oito horas com cada um dos docentes.

Produziram-se 22 documentos para análise, 11 resultantes das entrevistas e 11 das observações. Na organização e no tratamento dos dados, utilizou-se a triangulação articulada à análise temática de conteúdo de Bardin (2010), incluindo três fases cronológicas: pré-análise, exploração do material e tratamento dos resultados.

O estudo foi aprovado pelo Comitê de Ética em Pesquisa da Universidade Federal de Santa Catarina (UFSC), com o protocolo n. 4.410/2012. Com o objetivo de garantir o sigilo e o anonimato, as falas utilizadas no manuscrito foram identificadas pela letra $\mathrm{E}$, seguida do número de ordem cronológica de realização das entrevistas; e as instituições onde foram realizadas as observações estão identificadas conforme o tipo de instituição e o número de ordem cronológica.

\section{Elementos que influenciam a prática de biossegurança na concepção dos docentes}

Em relação às práticas biosseguras desenvolvidas pelos docentes, destacaram-se os elementos que as influenciam, conforme relatado nas entrevistas, os quais estão descritos na Tabela 1 . O número de citações não corresponde ao total dos entrevistados porque cada participante poderia mencionar mais de um elemento, assim como foram associadas as menções a elementos que têm relação entre si. 
Tabela 1

Elementos facilitadores e dificultadores da prática de biossegurança

\begin{tabular}{lcc}
\hline Facilitam práticas biosseguras & No de citações & $\%$ \\
Materiais e equipamentos disponíveis e de fácil acesso & 09 & 69,24 \\
Conhecimento sobre a biossegurança & 04 & 30,76 \\
Total & 13 & 100 \\
& No de citações & $\%$ \\
Dificultam práticas biosseguras & 05 & 35,71 \\
Déficits na quantidade e qualidade do EPI & 05 & 35,71 \\
Infraestrutura inadequada nas instituições assistenciais & 04 & 28,58 \\
Laboratórios de ensino inadequados & 14 & 100 \\
Total & & \\
\hline
\end{tabular}

Fonte: As autoras.

Nota: EPI - equipamentos de proteção individual.

Além dos elementos facilitadores e dificultadores da prática de biossegurança, com base nos dados obtidos nas observações e nas entrevistas, foram apresentados os diversos elementos que interatuam no processo de tomada de decisão dos docentes ao praticar e ensinar ações biosseguras. Verificou-se que as ações dos docentes em relação à biossegurança são influenciadas, sobretudo, pela disponibilidade e pelo acesso aos materiais e equipamentos, mas também pela quantidade e qualidade dos equipamentos de proteção individual, pela infraestrutura das instituições assistenciais e laboratórios de ensino e pelo conhecimento dos docentes acerca do tema. Os resultados mostraram, ainda, que apesar de os docentes reconhecerem a importância dos EPIs, nenhum entrevistado mencionou o uso ou a importância dos EPCs e da proteção do meio ambiente.

\section{Disponibilidade, acesso, qualidade e quantidade de materiais e equipamentos de biossegurança}

O processo de trabalho do(a) enfermeiro(a) integra pessoas, materiais, equipamentos e ambiente físico durante a prestação de cuidados assistenciais diretamente aos usuários, o que pode, de acordo com a atividade a ser desenvolvida, contribuir para a exposição aos riscos ocupacionais. A biossegurança diz respeito à proteção à vida, envolvendo quem desenvolve o trabalho, 
a quem ele é dirigido (usuário/doente) e o espaço institucional, social e ambiental onde ele ocorre. As medidas de biossegurança criam barreiras entre os profissionais e os agentes danosos, e a disponibilização e o emprego correto e adequado de materiais e equipamentos contribuem para a proteção de docentes e discentes, assim como para o ensino no momento da atividade prática supervisionada.

Os hospitais e as unidades básicas de saúde são regidos por normas, regulamentações e protocolos de segurança, que devem ser respeitados pelos profissionais envolvidos, evitando-se assim a exposição aos agentes biológicos, capazes de promover agravos à saúde humana e ambiental (Teixeira e Valle, 2010).

Segundo os docentes entrevistados, o elemento mais significativo para a promoção de práticas biosseguras $(69,24 \%$ das citações) foi a disponibilidade e facilidade de acesso a equipamentos e materiais. Dentre eles, pode-se destacar: capela de fluxo laminar, luvas, óculos, avental, papel toalha, bandejas para transporte de materiais utilizados nos cuidados, pia, álcool gel e demais EPIs - como ilustrado na fala a seguir:

No hospital sempre tem os materiais necessários, eles cuidam bastante, (...) é um hospital que dá segurança, tem sempre material, tem luvas, sempre tem papel toalha, mesmo que não tenha luvas de procedimento (...) a gente pode pegar as luvas estéreis. Tem os sabões necessários (...) todos os quartos têm álcool gel, têm a pia, têm papel toalha (...) o que a gente tem que ter é esse cuidado de estar fazendo (E11).

Esse cenário é o esperado, uma vez que as instituições de saúde que cedem espaço às atividades práticas são regulamentadas pela NR 32, que dispõe sobre a necessidade de prover ambientes seguros e adequados à prestação de cuidados (Conselho Regional de Enfermagem de Santa Catarina, 2011; Brasil, 2005b). Tais medidas, quando cumpridas pelas instituições, contribuem para o agir seguro, conforme relato dos docentes entrevistados:

A gente tem os materiais à disposição (...) e agora já tem o avental, o EPI (E4).

Nestes campos (...) os equipamentos estão lá, eu encontro à disposição, eu não senti falta de procurar um material e não ter no campo (...) eles preparam, fazem o acondicionamento e a desinfecção e esterilização do material, lá eles têm um expurgo e têm esterilização de material e têm o EPI direitinho, têm os óculos, a máscara (E1).

Realmente eu não tive problema com relação aos equipamentos de biossegurança, lá na unidade, dispõem de todos, se precisarem de óculos eles dispõem, se precisar de luva têm à vontade (E2). 
Entretanto, quando os equipamentos e materiais não se encontram disponíveis ou estão em condições precárias, é criada uma situação que não favorece a adoção e o uso das práticas biosseguras.

Os docentes pesquisados relataram que muitas instituições que admitem a realização das atividades práticas supervisionadas nem sempre estão preparadas para receber docentes e discentes, não fornecendo materiais e equipamentos em boas condições de uso e com fácil acesso. Tal fato é considerado pelos participantes, conforme expressões que seguem, como gerador de dificuldade à execução das ações que envolvem técnicas e procedimentos seguros.

Tem, mas aqueles que compõem a rotina, aqueles que são mais usados, como luva, máscara, o óculos de acrílico, você não acha. Se quiser utilizar para fazer um procedimento não tem o óculos, nós que temos que levar, a escola é que tem que levar, porque o hospital não tem (E7).

Seria mais no caso de que é pouca luva, que tem que estar controlando o uso das luvas (E2).

A legislação brasileira que trata dos estágios de estudantes assegura ao aluno o fornecimento do EPI e do EPC, responsabilizando as instituições pela garantia da disponibilização de materiais seguros e descartáveis, bem como determinando seguimento para os casos de exposição a material biológico (Brasil, 2008a). A NR 6 regulamenta a utilização dos EPIs, definindo que estes devem ser adequados em conformidade com a prevenção do risco a que se está exposto, estando em perfeitas condições de conservação e funcionamento, e também resguarda que os empregadores devem oferecer treinamento aos trabalhadores no que se refere ao uso adequado. Ante qualquer irregularidade no cumprimento da norma, deve-se comunicar ao Ministério do Ministério do Trabalho e Previdência Social (Brasil, 2001).

Algumas vezes, os materiais e equipamentos encontram-se disponíveis e acessíveis ao grupo docente e discente; no entanto, eles não são confortáveis e adequados às diferenças físicas, ou seja, ao tamanho e biótipo dos indivíduos. Tais situações dificultam e até inviabilizam o uso dos EPIs, conforme relato do docente e a nota de observação a seguir destacados:

A dificuldade é, por exemplo, os óculos escorregam, são feitos de tamanho único e às vezes as pessoas têm feições menores, que embaça (...) eu não vou utilizar então (E2).

Na unidade, a maioria dos funcionários era homens, e o local dispunha somente de luvas de procedimento do tamanho G. Os alunos mostraram muita dificuldade 
de realizar o procedimento, as luvas eram grandes e não estavam adequadas ao tamanho das mãos. A professora, percebendo o fato, orientou seus alunos a usarem luvas cirúrgicas, havendo todos os tamanhos. Enfatizou que não era o ideal pelo alto custo, mas, devido às técnicas que foram sendo assumidas pelo grupo, fazia-se necessário o uso seguro das luvas (nota de observação, H1).

A professora renormalizou com base no conhecimento, no que o meio lhe oferecia (disponibilidade das luvas cirúrgicas) e no valor que atribuía à segurança, procurando minimizar o risco na realização do procedimento. Escolheu a segurança em detrimento da economia, usando luvas mais caras. Neste caso o docente transgrediu, no sentido expresso por Schwartz e Durrive (2010), não seguindo estritamente o recomendado nas normativas, porém procurando o equilíbrio entre as suas, de um coletivo, das organizações (do serviço e do ensino) e as do contexto de trabalho no qual estava inserido. Segundo os autores, a transgressão mexe com os valores do sujeito e pode ser um sinal de vitalidade, que nessa situação pareceu associar as práticas seguras à proteção dos envolvidos no trabalho ou à segurança da vida.

\section{Conhecimento dos docentes sobre biossegurança}

O domínio de conceitos, normas e protocolos é essencial para a prática da biossegurança, mas tem seus limites, porque o agir profissional é resultante de uma articulação dialética entre conhecimentos adquiridos, experiência prévia e valores que vão orientar escolhas na relação com o meio infiel (Schwartz, 2013).

O conhecimento dos docentes sobre biossegurança sensibiliza para condutas e posturas apropriadas diante de condições de trabalho que, em geral, não correspondem ao esperado ou descrito nas normas. A apropriação do conhecimento é um elemento facilitador que contribui para a adoção de práticas biosseguras, porém as falas demonstraram que o conhecimento pessoal sobre o tema é incipiente.

Esse conhecimento a gente tem que buscar mais. Nem sempre a gente busca, por ter outros focos de pesquisa (...) estou bem ciente que poderia buscar mais (E9).

A gente passa por ela quando a gente estuda, e se esse não é nosso objeto de estudo dali para frente, acabou. (...) a gente tá preocupada em ensinar psiquiatria e não biossegurança (E6).

Observa-se que a busca de conhecimentos é guiada pela necessidade do trabalho, e diante da imensidão de normas a dominar e a construir para agir 
nas situações de trabalho, as de biossegurança não se apresentam como prioritárias, como ilustrado a seguir:

Eu acho que tenho pouco conhecimento sobre estas questões de biossegurança, por exemplo, com relação a manuseio de antibióticos, ou de outros medicamentos agressivos. Deveria dar mais atenção às normas, deveria saber mais. Não tenho bem claro em mente que devo estudar [este tema] (E5).

O conhecimento do que eu vou fazer (...) no estágio, o aluno se feriu e agora para onde que eu encaminho, como é isso daí? (...) nem sempre é claro para o próprio profissional (E9).

Os docentes expressam conhecimento sobre a biossegurança ao relatarem que são saberes prévios advindos de suas formações, na graduação ou na especialização. A apropriação desses saberes, tais como em relação aos agentes etiológicos e sua patogenicidade, poderia contribuir para a incorporação das medidas de proteção (Teixeira e Valle, 2010).

Não há procura de capacitação relativa ao tema por parte dos docentes como inerente ao fazer do(a) enfermeiro(a). O conhecimento mais aprofundado sobre biossegurança ocorre geralmente na pós-graduação e é pouco procurado em outros âmbitos de formação, como evidenciam as falas:

$\mathrm{O}$ fato de eu ter feito o mestrado nesta área e também ter feito as disciplinas de saúde e segurança do trabalhador e de biossegurança, e mais o estudo da dissertação me deram bastante conhecimento sobre a biossegurança (E4).

Conhecimento básico poderia ser com certeza, mais aprimorado, a gente tem um conhecimento que se tem na graduação, mas eu acredito que poderia ser mais aprofundado (...) para estar respaldando a prática (E8).

É fundamental que os docentes se apropriem do saber científico que envolve a biossegurança, oportunizando debates, reflexões e atualizações, tendo como propósito buscar instrumentos para a preservação da vida em qualquer espaço de trabalho (Andrade e Sanna, 2007).

\section{Infraestrutura das instituições assistenciais}

O conjunto de requisitos que envolvem a prevenção e a minimização dos riscos inclui infraestrutura adequada, procedimentos padronizados e um ambiente com padrões de qualidade e conforto. Esses aspectos, quando não respeitados, contribuem para expor os trabalhadores à sobrecarga, aos aci- 
dentes, à contaminação e ao adoecimento, como evidenciam os seguintes depoimentos:

O ambiente em si, os próprios profissionais, a estrutura dos hospitais, das unidades de saúde não favorecem, ou favorecem a possibilidade de acidentes e de contaminação (E5).

Os alunos se descolam entre o posto de enfermagem até a sala de procedimentos, com o material nas mãos. A unidade não tem bandejas, as equipes não utilizam. Na sala de procedimentos, não constam recipientes para o descarte de materiais perfurocortantes, e o aluno, novamente, com o material contaminado e perfurante se desloca pela unidade, entre pacientes, profissionais e pessoal da limpeza, indo ao posto de enfermagem para desprezar o material utilizado (nota de observação UPA1).

A NR 32 determina que os locais de trabalho devem ser organizados a fim de evitar deslocamentos e esforços por parte dos trabalhadores, e os recipientes de perfurocortantes devem estar em locais de fácil acesso para o descarte seguro do resíduo. Na necessidade do transporte de materiais comprometedores à saúde e à segurança, deve-se executar com auxílio mecânico, evitando-se o contato ou derramamento de substâncias infectocontagiosas (Coren/SC, 2011; Brasil, 2005b).

Nos locais para higienização dos pacientes, há problemas estruturais terríveis, e isso dificulta da gente manter o ambiente dentro das normas, daquilo que é aceitável, até para o bom senso (E6).

Alguns locais, eles têm uma estrutura que não facilita, têm uma estrutura que está arcaica muitas vezes, que não está adequada, e que muitas vezes ela nem foi feita de acordo com a Anvisa RDC n. 50/2002 (Brasil, 2002), ou são ambientes adaptados, ambientes que muitas vezes precisam de reforma. Às vezes, a estrutura administrativa não consegue dar conta, então isso dificulta, dificulta bastante (E8).

Para Telles e Alvarez (2004), o trabalho prescrito requer um conjunto de fatores necessários à sua execução. As autoras consideram o ambiente físico fundamental para que as situações reais de trabalho possam ser desenvolvidas, contribuindo para superar o distanciamento entre o prescrito e o realizado - conforme expressa o docente em seu relato e o descrito na observação da pesquisadora:

Com relação ao campo de estágio, às vezes a dificuldade é pelo tamanho do espaço, no postinho de enfermagem corre o risco de (...) se contaminarem com uma 
agulha, espetando um dedo, realmente pelo espaço que tem naquele local, que às vezes é um espaço pequeno e tem várias pessoas ali dentro, às vezes vão se batendo, toda hora pedindo licença com a bandeja, então isso é que dificulta (E2).

Os procedimentos, como punções venosas ou injetáveis, são realizados em uma sala de nebulização, onde não há local adequado para o descarte de materiais perfurocortantes ou do lixo contaminado. Estes recipientes ficam atrás de um biombo, $o$ que dificulta o acesso para o descarte seguro do material. Neste local, verificou-se que a bandeja utilizada por uma das alunas foi colocada junto com os pertences pessoais dos pacientes. Quando o movimento de pacientes é intenso, a ordem e a qualidade do atendimento ficam comprometidas. Alunos, professor e a equipe estão, ao mesmo tempo, preparando e administrando medicamentos, em espaços pequenos, mal ventilados, com impossibilidade de realizar a lavagem das mãos (nota de observação, UPAl).

No relato dos participantes e na observação do pesquisador sobre as situações de trabalho dos docentes, está apontado que neste contexto adverso há influência das organizações, do ambiente, das relações pessoais. Que essa ação é sempre singular e a realidade das atividades nem sempre condizem com o prescrito. Significa que há "liberdade, limitada pelos constrangimentos incontornáveis - percebidos por todos - mas também que não há uma única maneira boa de fazer as coisas. Sempre há escolhas a fazer, por mais ínfimas que sejam" (Trinquet, 2009, p. 157).

\section{Laboratórios de ensino: adequação e estrutura}

Durante a formação de novos profissionais, na graduação ou no nível médio, o(a) enfermeiro(a) que atua como docente enfrenta os desafios e as dificuldades encontrados no cenário assistencial. Os laboratórios de ensino têm a função de oportunizar a simulação de técnicas e procedimentos. Neles, os docentes devem contextualizar teoria e prática e propiciar um ensino coerente ao que se espera dos novos profissionais, estimulando a adoção de condutas e hábitos pertinentes à sua segurança, do outro e do meio ambiente. Os docentes entrevistados disseram que os laboratórios de ensino deveriam propiciar condições adequadas para que o processo de aprendizagem pudesse se desenvolver - e quando inadequados dificultavam o ensino da biossegurança.

Na instituição em que eu trabalho, nós temos um pouco de dificuldades em relação aos laboratórios, eles não são organizados de forma a atender às normas, muitas vezes não têm uma pia para lavagem das mãos, o que é algo básico para 
evitar contaminação, e temos muitas dificuldades em relação às aulas práticas, principalmente pela falta de estrutura de um laboratório (...) por esta dificuldade a gente tem que ir fora da instituição, no ambiente hospitalar, para realizar as aulas práticas com os alunos (E3).

Nós temos no laboratório de enfermagem (...) alguns cuidados com o aluno, mesmo que não vá fazer nenhum procedimento invasivo, mas o hábito de estar de sapato fechado, de calça, a utilização do jaleco lá dentro, então mesmo que a gente vá fazer ou trabalhar uma sondagem vesical, mas a gente vai fazer no boneco, mas já se tem essa preocupação, pois cria o hábito, a cultura de estar utilizando (E7).

No que diz respeito à necessidade de medidas de proteção nos laboratórios de ensino, a literatura registra que as aulas práticas são fundamentais para a formação de valores relativos à importância do desenvolvimento de técnicas corretas, incluindo a proteção de professores, alunos e meio ambiente (Hirata, 2012). Em uma aula prática, a “organização deve ser muito bem estabelecida, planejada e descrita de forma clara com os detalhes para um principiante naqueles procedimentos", e o laboratório de ensino, assim como o de pesquisa e de biotecnologia, é local "de constante aprendizado tanto para o professor quanto para os alunos". Nesses ambientes é imprescindível a harmonia com o ambiente de trabalho, além de "boa interação entre o trabalho e as ferramentas de ensino", de modo que o processo ensino-aprendizagem possa ocorrer de "forma harmoniosa, agradável e sem intercorrências", contribuindo para a formação acadêmico-científica e profissional (Hirata, 2012, p. 1-2).

Os documentos analisados (NR 32, NR 06, lei n. 11.788/2008) mostram prescrições orientadoras das práticas, da realização dos estágios supervisionados e de como organizar os serviços e os laboratórios de ensino, visando proteger profissionais, usuários, meio ambiente e docentes (Brasil, 2008a). No entanto, muitos locais de prática (laboratórios e instituições assistenciais) não dispõem de EPIs em quantidade e qualidade necessárias, assim como os ambientes, muitas vezes, são adaptados, com instalações improvisadas e precárias, em condições insalubres e inseguras. Essa realidade influencia o processo de tomada de decisão, ora no sentido da realização de práticas biosseguras, ora no de ações imprudentes e menos protetoras.

Durante a realização das técnicas e dos procedimentos assistenciais e de ensino, os docentes confrontam os seus conhecimentos e crenças com as condições concretas encontradas nos diversos cenários de prática. Nesse processo multideterminado, o prescrito e o real podem aproximar-se ou se distanciar (Schwartz, 2011; Canalli, Moriya e Hayashida, 2011). Nas circunstâncias reais do trabalho, "os trabalhadores se mobilizam e, para dar conta 
da tarefa, ao mesmo tempo que lutam pela sua saúde, (re)criam estratégias e táticas em um movimento permanente de (re)normatização" (Brito et al., 2011, p. 27).

A biossegurança deve estar inserida nos espaços educacionais de modo transversal ao currículo e ser incorporada aos programas de educação permanente, envolvendo o coletivo de qualquer ambiente de trabalho. “Não basta construir laboratórios com equipamentos adequados de última geração e disponibilizar material de segurança sem investir em educação e treinamento, os quais devem ser considerados instrumentos contínuos, e não temporários" (Mastroeni, 2008, p. 2).

\section{Considerações finais}

Os resultados da pesquisa sugeriram que, na prática da biossegurança realizada por enfermeiros(as) docentes durante estágio supervisionado, o conhecimento acerca das normas prescritas se constitui em um valor com potencial de influenciar, positivamente, as ações dos docentes. Os participantes consideraram que a biossegurança é importante de ser praticada e ensinada. No entanto, mostraram que, para agir, não basta conhecer; é necessário que os cenários de prática propiciem condições para a realização da assistência e do ensino protetor.

Ao ensinar, os docentes expressam o saber que adquiriram na graduação e na pós-graduação, com suas fortalezas e insuficiências. Na experiência da docência, confrontam tal saber com as condições concretas dos laboratórios de ensino e dos cenários de prática das instituições assistenciais. Esse contexto influencia o processo de tomada de decisão em cada atividade de ensino realizada.

O trabalho em saúde requer, além de profissionais habilitados, com saber científico necessário para prestar cuidados às pessoas com carências do campo da saúde, a disponibilidade de instrumentos de trabalho e condições adequadas à execução de ações seguras e de qualidade. As escolas profissionalizantes, responsáveis pela formação de um dos maiores contingentes de profissionais de enfermagem no país, desempenham um papel fundamental para a construção da cultura de práticas biosseguras, o que influenciará na qualidade da assistência em saúde e enfermagem.

A pesquisa evidenciou que o acesso ao conhecimento, a disponibilidade de EPIs em quantidade e qualidade, a organização e a estrutura adequada dos ambientes assistenciais e de ensino, no que tange à biossegurança, contribuem para as ações biosseguras. A improvisação e as adaptações a que os docentes são submetidos colaboram para a exposição desnecessária e colocam todos os envolvidos e o ambiente em situação de risco. 
Ao se partir da premissa de que é possível a formação de profissionais que adotem práticas biosseguras, as instituições de ensino necessitam propiciar espaços que sensibilizem os educandos no que diz respeito à biossegurança. É nos espaços escolares com cultura voltada para a prevenção e a construção de ambientes saudáveis que a realidade da práxis pode ser modificada. As capacitações e a educação permanente sobre o tema são imprescindíveis, por tratar-se de uma temática ainda pouco debatida pelos docentes do ensino médio profissionalizante da área da enfermagem.

A presente pesquisa baseou-se na concepção dos docentes, mas alunos, gestores e demais profissionais também são sujeitos dos cenários de ensino, o que sugere maior complexidade do fenômeno, podendo constituir-se em novos objetos de investigação.

\section{Colaboradores}

Gerusa Ribeiro redigiu o artigo. Denise Elvira Pires de Pires participou como orientadora e contribuiu no desenvolvimento do texto. Magda Duarte dos Anjos Scherer realizou a revisão do artigo.

Resumen La bioseguridad es un componente central a ser considerado para que los profesionales ejecuten sus actividades minimizando los daños a su salud y a la de los usuarios de los servicios de salud. Las instituciones educativas y los(as) enfermeros(as) docentes tienen un papel fundamental en este proceso. Con el objetivo de comprender la práctica de la bioseguridad realizada por enfermeros(as) docentes durante la supervisión de la pasantía de alumnos de cursos técnicos de enfermería, se realizó una investigación exploratoria descriptiva, de enfoque cualitativo. Los datos se tomaron en el año 2012, con 11 enfermeros(as) docentes de dos instituciones de la red federal de educación profesional, científica y tecnológica en la región sur de Brasil. Se utilizó la triangulación metodológica con datos obtenidos por medio de estudio documental, entrevista semiestructurada y observación, orientados por el análisis temático de contenido de Bardin. Los resultados mostraron que las acciones de los docentes con relación a la bioseguridad están afectadas por la disponibilidad y acceso a los materiales y equipos, por la cantidad y calidad de los equipos de protección personal, por la infraestructura de las instituciones asistenciales y laboratorios de enseñanza y por el conocimiento del tema. Se concluyó que las acciones protectoras en la práctica docente están afectadas por el conocimiento, por las condiciones de trabajo y por las elecciones de los sujetos.

Palabras clave exposición a agentes biológicos; bioseguridad; enfermería; educación técnica en enfermería; salud del trabajador. 


\section{Notas}

${ }^{1}$ Instituto Federal de Santa Catarina, Florianópolis, Santa Catarina, Brasil.

$<$ gerusa@ifsc.edu.br>

Correspondência: Rua Heitor Luz, 97, apartamento 1.009, Centro, CEP 88015-500, Florianópolis, Santa Catarina, Brasil.

2 Universidade Federal de Santa Catarina, Centro de Ciências da Saúde, Departamento de Enfermagem, Florianópolis, Santa Catarina, Brasil.

<piresdp@yahoo.com>

3 Universidade de Brasília, Departamento de Saúde Coletiva, Brasília, Distrito Federal, Brasil.

$<$ magscherer@hotmail.com>

$4 \mathrm{O}$ artigo é produto de dissertação de mestrado, intitulada Enfermeiro(a), docente na atividade prática supervisionada: a biossegurança prescrita e realizada, de autoria de Gerusa Ribeiro, apresentada em 2012 no Curso de Pós-Graduação em Enfermagem da Universidade Federal de Santa Catarina, em Florianópolis.

\section{Referências}

ANDRADE, Andréia C.; SANNA, Maria C. Ensino de biossegurança na graduação em enfermagem: uma revisão da literatura. Revista Brasileira de Enfermagem, Brasília, v. 60, n. 5, p. 569-572, set./out. 2007.

BARDIN, Laurence. Análise de conteúdo. Lisboa: Edições 70, 2010.

BRASIL. Agência Nacional de Vigilância Sanitária. Resolução RDC n. 50, de 21 de fevereiro de 2002. Dispõe sobre o Regulamento Técnico para planejamento, programação, elaboração e avaliação de projetos físicos de estabelecimentos assistenciais de saúde. Brasília: Ministério da Saúde, 2002. Disponível em: <www.anvisa.gov.br/anvisalegis/resol/ 2002/50_02rdc.pdf> Acesso em: 29 jun. 2016.

BRASIL. Lei n. 11.105, de 24 de março de 2005. Regulamenta os incisos II, IV e V do $\S 1^{\circ}$ do art. 225 da Constituição Federal, estabelece normas de segurança e mecanismos de fiscalização de atividades que envolvam organismos geneticamente modificados - OGM e seus derivados, cria o Conselho Nacional de Biossegurança - CNBS, reestrutura a Comissão Técnica Nacional de Biossegurança CTNBio, dispõe sobre a Política Nacional de Biossegurança - PNB, revoga a lei n. 8.974, de 5 de janeiro de 1995, e a medida provisória n. 2.191-9, de 23 de agosto de 2001, e os arts. $5^{\circ}, 6^{\circ}, 7^{\circ}, 8^{\circ}, 9^{\circ}, 10$ e 16 da lei n. 10.814, de 15 de dezembro de 2003, e dá outras providências. Diário Oficial da República Federativa do Brasil, Poder Executivo, Brasília, DF, 24 mar. 2005a. Seção 1, p. 1. Disponível em: <www2.camara.leg.br/legin/ fed/lei/2005/lei-11105-24-marco-2005-536209normaatualizada-pl.pdf $>$. Acesso em: 29 jun. 2016.

BRASIL. Lei n. 11.788 , de 25 de setembro de 2008. Dispõe sobre o estágio de estudantes, altera a redação do art. 428 da Consolidação das Leis do Trabalho - CLT e dá outras providências. Diário Oficial da República Federativa do Brasil, Poder Executivo, 
Brasília, DF, 26 set. 2008a. Seção 1, p. 3. Disponível em: <www.planalto.gov.br/ccivil_03/ _ato2007-2010/2008/lei/111788.htm > Acesso em: 29 jun. 2016.

BRASIL. Ministério da Saúde. Aprova a Classificação de Risco dos Agentes Biológicos elaborada em 2010, pela Comissão de Biossegurança em Saúde (CBS), do Ministério da Saúde. Portaria n. 1.914 de 9 de agosto de 2011. Diário Oficial da República Federativa do Brasil. Poder Executivo, Brasília, DF, 11 ago. 2011. Seção 1, p. 74. Disponível em: <www.anbio.org.br/site/files/palestras/ Portaria \% 201.914\%20de\%209\%20de\% 20 agosto $\% 20$ de $\% 202011-\% 20$ classificacao $\% 20$ de $\% 20$ riscos $\% 20$ biologicos.pdf > . Acesso em: 30 jun. 2016.

BRASIL. Parecer CNE/CEB No 11/2008. Proposta de Instituição do Catálogo Nacional de Cursos Técnicos de Nivel Médio. Brasília, nov. p. 1-180, 2008b.

BRASIL. Portaria n. 485, de 11 de novembro de 2005. Aprova a norma regulamentadora NR 32. Brasília: Ministério do Trabalho e Previdência Social, 2005b. Disponível em: $<$ http://sbbq.iq.usp.br/arquivos/seguranca/ portaria485.pdf $>$ Acesso em: 29 jun. 2016.

BRASIL. Secretaria de Inspeção do Trabalho. Portaria n. 25, de 15 de outubro de 2001. Altera a norma regulamentadora que trata de equipamento de proteção individual - NR 6 e dá outras providências. Brasília: Ministério do Trabalho e Previdência Social, 2001. Disponível em: <www.trabalhoseguro.com/ Portarias/port_25_2001_altera_nr6.html>. Acesso em: 29 jun. 2016.

BRITO, Jussara et al. O trabalho nos serviços públicos de saúde: entre a inflação e a ausência de normas. In: ASSUNÇÃO, Ada A.; BRITO, Jussara (orgs.). Trabalhar na saúde: experiências cotidianas e desafios para a gestão do trabalho e do emprego. Rio de Janeiro: Editora Fiocruz, 2011.

CANALLI, Rafaela T. C.; MORIYA, Tokico M.; HAYASHIDA, Miyeko. Prevenção de acidentes com material biológico entre estudantes de enfermagem. Revista de Enfermagem, Rio de Janeiro, v. 19, n. 1, p. 100-106, jan./mar. 2011.

CONSELHO REGIONAL DE ENFERMAGEM DE SANTA CATARINA (COREN/SC). Normas regulamentadoras (NR) do Ministério do Trabalho e Emprego relativas à saúde $\mathrm{e}$ segurança do trabalhador de saúde. In: SILVA, Rosilda V. et al. (orgs.). Saúde do trabalhador $e$ atualização da legislação. Série Cadernos Enfermagem. Florianópolis: Letra Editorial, 2011. v. 2. p. 132.

CONSELHO REGIONAL DE ENFERMAGEM DE SANTA CATARINA (COREN/SC). Estatísticas de Profissionais 542a, 16 de junho de 2016. Disponível em: <www.corensc.gov. $\mathrm{br} / \mathrm{c}=\mathrm{f} \& \mathrm{t}=9 \& \mathrm{cod}=27>$. Acesso em: 30 jun. 2016.

\section{CONSELHO REGIONAL DE ENFERMAGEM} DO RIO GRANDE DO SUL (COREN/RS). Números de inscritos ativos por categoria profissional. Disponível em: <www.portalcoren-rs. gov.br/index.php? categoria $=$ servicos $\&$ pagina=estatisticas $>$. Acesso em: 30 jun. 2016.

CosTA, Marco A. F.; CosTA, Maria F. B. Biossegurança de OGM: saúde humana e ambiental. Rio de Janeiro: Papel e Virtual, 2003.

HIRATA, Mario H. O laboratório de ensino e pesquisa e seus riscos. In: HIRATA, Mario H.; HIRATA, Rosario D. C.; FILHO, Jorge M. Manual de biossegurança. Barueri: Manole, 2012. p. 1-12.

MASTROENI, Marco F. A difícil tarefa de praticar a biossegurança. Ciência e Cultura, São Paulo, v. 60, n. 2, p. 1-2, 2008.

MINAYO, Maria C. S.; ASSIS, Simone G.; SOUZA, Edinilsa R. (orgs.). Avaliação por triangulação de métodos. Rio de Janeiro: Editora Fiocruz, 2006.

MINAYO, Maria C. S.; GOMES, Suely F. D. Pesquisa social, teoria, método e criatividade. 26. ed. Petrópolis: Vozes, 2012.

ODA, Leila M.; SANTOS, Bruna C.; Memórias da biossegurança e biosseguridade: de 
Asilomar à biologia sintética. In: HIRATA, Mario H.; HIRATA, Rosario D. C.; FILHO, Jorge M. Manual de biossegurança. Barueri: Manole, 2012. p. 295-305.

PEREIRA, Maria E. C. et al. Reflexões sobre conceitos estruturantes em biossegurança: contribuições para o ensino de ciências. Ciências e Cognição, Rio de Janeiro, v. 14, n. 1, p. 296-303, mar. 2009.

PIRES, Denise P. A enfermagem enquanto disciplina, profissão e trabalho. Revista Brasileira de Enfermagem, Brasília, v. 62, n. 5, p. 739-744, set./out. 2009.

POLIT, Denise F.; BECK Cheryl T.; HUNGLER, Bernadette P. Fundamentos de pesquisa em enfermagem: avaliação de evidências para a prática da enfermagem. 7. ed. Porto Alegre: Artmed, 2011.

SCHWARTZ, Yves. Conceituando o trabalho, o visível e o invisível. Trabalho, Educação e Saúde, Rio de Janeiro, v. 9, n. 1, supl. 1, p. 19-45, 2011.

SCHWARTZ, Yves. Conception de la formation professionnelle et double anticipation. Education Permanente: Revue internationale de référence em formation des adultes, Paris, v. 197, n. 4, p. 13-29, 2013.
SCHWARTZ, Yves; DURRIVE, Louis. Trabalho e ergologia. In: SCHWARTZ, Yves; DURRIVE, Louis (orgs.). Trabalho \& Ergologia: conversas sobre a atividade humana. 2. ed. Niterói: EdUFF, 2010. p. 25-36.

TEIXEIRA, Pedro; VALLE, Silva. Biossegurança: uma abordagem multidisciplinar. Rio de Janeiro: Editora Fiocruz, 2010.

TELLES, Ana L.; ALVAREZ, Denise. Interfaces ergonomia-ergologia: uma discussão sobre trabalho prescrito e normas antecedentes. In: FIGUEIREDO, Marcelo et al. (orgs.) Labirintos do trabalho: interrogações e olhares sobre o trabalho vivo. Rio de Janeiro: DP\&A, 2004. p. 63-90.

TRINQUET, Pierre. Prévenir les dégats du travail: l'ergoprevention. Paris: Presses Universitaires de France (PUF), 2009.

WONG, Becky J. Basic biosafety principles. EH\&S Academy. UCSD Biosafety Officer. Riverside, Califórnia. 2009. Disponível em: <www. ehs.ucr.edu/ehsacademy/presentations/ biosafety.ppt>. Acesso em: 30 jun. 2016.

Recebido em 03/12/2014

Aprovado em 19/06/2015 